\title{
MANFAAT MODAL SOSIAL DALAM KETAHANAN SOSIAL RUMAH TANGGA PEDAGANG SAYUR KELILING DI MAHAKARYA KAMPUNG 2 KECAMATAN LUHAK NAN DUO KABUPATEN PASAMANBARAT
}

\author{
Osi Oktaviani' ${ }^{1}$ Irwan $^{2}$, Zusmelia $^{3}$
}

\section{Universitas PGRI Sumatera Barat}

osioktaviani33@gmail.com

\begin{abstract}
ABSTRAK
Perkembangan makro ekonomi Indonesia saat ini mengalami penurunan hal ini dapat dilihat dari pertumbuhan ekonomi di Indonesia pada April 2020. Penurunan pertumbuhan ekonomi tersebut berada sektor informal. Kegiatan sektor informal ini adalah salah satunya pedagang sayur keliling. Dengan memanfaatkan modal sosial yang ia miliki pedagang sayur keliling mampu bertahan dalam ketahanan sosial rumah tangganya dengan pendapatan dibawah UMR. Tujuan Penelitian adalah menganalisis manfaat modal sosial dan ketahanan rumah tangga pedagang sayur keliling. Penelitian ini menggunkan pendekatan kualitaif, denganmetodepengumpulan data observasi, wawancaramendalam dan pengumpulan data dokumen. Analisis data menggunkan model Miles dan Huberman. Hasil penelitian menunjukan bahwa manfaat modal sosial pedagang sayur keliling yaitu: 1) terbangunya kepercayaan anatar pedagang sayaur keliling dan pelangan untuk memberikan pinjaman serta memperkuatkan hubungan sosial antara pedagang dan pembeli. 2). Mampu memperlus jaringan, sebagai jembatan mendapatkan pelanggan baru dan terbentuknay kelompok arisan sesama pedagang. 3) terbangunya kesepakatan antara pedagang dan pembeli dalam tindakan ekonomi serta pedagang mampu bertahan dalam ketahanan rumah tang ga dengan tidak membiarkan modal mereka berhenti karena pelanggan telat berhutang.
\end{abstract}

Kata Kunci: Ketahanan Sosial, Modal Sosial, Pedagang Sayur Keliling

\begin{abstract}
Indonesia's macroeconomic development is currently experiencing a decline, this can be seen from the economic growth in Indonesia in April 2020. The decline in economic growth is in the informal sector. One of the activities of this informal sector is mobile vegetable traders. By utilizing the social capital that he has, the traveling vegetable seller is able to survive in the social security of his household with an income below the minimum wage. The purpose of the study was to analyze the benefits of social capital and household resilience of mobile vegetable traders. This study uses a qualitative approach, with the methods of collecting observation data, in-depth interviews and document data collection. Data analysis using Miles and Huberman model. The results show that the benefits of social capital for mobile vegetable traders are: 1) building trust between traveling vegetable traders and customers to provide
\end{abstract} Osi Oktaviani', Irwan², Zusmelia ${ }^{3}$

Universitas PGRI Sumatera Barat

Jalan Gunung Panggilun,

Kec. Padang Utara, Kota Padang

JUR NAL ILMIAH DINAMIKA SOSIAL 4 (1) 2020| 292

E-mail: irwan7001@gmail.com 
loans and strengthen social relations between traders and buyers. 2). Able to expand the network, as a bridge to get new customers and the formation of social gathering groups of fellow traders. 3) the establishment of an agreement between traders and buyers in economic action and traders are able to survive in household resilience by not letting their capital stop because customers are late in debt.

Keywords: Mobile Vegetable Traders, Social Capital, Social Resilience

\section{PENDAHULUAN}

Perkembangan makro ekonomi Indonesia saat ini mengalami penurunan, hal ini dapat dilihat dari pertumbuhan ekonomi di Indonesia pada April 2020 IMF memangkas proyeksi pertumbuhan ekonomi global pada tahun 2020 menjadi -3,0\% dari sebelumnya 3,3\% (yoy) (Ika, 2020). Hal ini menunjukan bahwa pertumbuhan ekonomi di Indonesia saat ini sedang mengalami penurunan. Penurunan pertumbuhan ekonomi tersebut dalam sektor informal. Kegiatan sektor informan ini adalah salah satunya pedagang sayur keliling. Pedagang sayur keliling adalah Pedagang sayur keliling adalah pedagang yang melakukan perdagangan tidak di tempat dagang seperti pasar atau pusat perbelanjaan sayuran melainkan dengan cara berkeliling menggunakan sepeda motor dengan keranjang sayurana. Pedagang sayur keliling berjualan setiap hari dari pukul 06.30-11.00 WIB. Pedagang sayur keliling kadang kala memiliki hubungan dalam bentuk patron clien dengan pelanggannya sehingga memunculkan kepercayaan (trust) sesama pedagang dan pembeli. Karena mereka memahami bahwa modal tidak hanya modal uang akan tetapi juga berupa mosal sosial, hal ini jugalah yang dijumpaidalam modal sosial yang didalamnya mengandalkan kepercayaan, dari kepercayaan itu pula akan menciptakan jejaring sosial (Rofiq, 2007). Sejalan dengan pendapat Fukuyama (2002) yang menyatakan bahwa modal sosial adalah kemampuan yang timbul dari adanya kepercayaan (trust) dalam sebuah komunitas. Perilaku atau tindakan tersebut salah satu unsur untuk menguatkan kerjasama antara pedagang dan pembeli. Hal yang sama juga terjadi pada pedagang sayur keliling di Mahakarya Kampung 2 Kecamatan Luhak Nan Duo Kabupaten Pasaman Barat.

Berdasarkan hasil observasi awal yang dilakukan oleh peneliti, pendapatan pedagang sayur keililing dapat dikelompokan sejumlah Rp.500.000-Rp.1.000.000 per bulan (Observasi tanggal 29 Desember 2020). Hal ini menunjukan Pendapatan pedagang sayur keliling tersebut termasuk pendapatan rendah bila dibandingkan dengan UMR Keputusan Gubernur Nomor 562/600/ Tahun 2020 sebesar Rp2.484.041 per bulan. Walaupun pendapatan pedagang sayur keliling dikatakan rendah tetapi mereka percaya memberikan hutang kepada pembeli. Kepercayaan merupakan salah satu unsuer dari modal sosial tidak hanya antara pedagang dan 
pembeli, tetapi modal sosial yang dimiliki pedagang sayur agar bertahan dalam ketahanan sosial rumah tangga. Sunarti (2001) ketahanan rumah tangga juga mengandung maskud sebagai kemampuan rumah tangga untuk mengembangkan dirinya secara optimis, sejahtera dan bahagia baik secara lahir dan batin. Ketahanan sosial rumah tangga menjadi faktor untuk perbaikan ekonomi dalam peningkatan kesejahteraan rumah tangga. Disamping itu juga, ketahanan sosial rumah tangga secara teoritis dianggap mampu menjembatani kekuatan modal sosial dalam bentuk jaringan, kepercayaan dan aturan yang telah disepakati bersama (Cahyaningtyas et al. 2016). Ketahanan sosial rumah tangga pedagang sayur keliling dengan pendapatan dibawah UMR, yaitu dengan modal sosial yang dimiliki. Berdasarkan hal tersebut maka peneliti tertarik untuk menelusuri lebih jauh persoalan pemanfaatan modal sosial pedagang sayur keliling.

\section{KAJIAN TEORI}

Penelitian ini menggunakan teori modal sosial yang dikemukakan oleh Putnam. Putnam memiliki latar belakang politik, dan kajian modal sosial pertamanya mengenai perbedaan pemerintahan Italia bagian utara dan selatan. Kinerja institusi di Italia bagian utara termasuk sukses yang disebabkan adanya hubungan timbal balik antara pemerintah dengan masyarakat sipil. Sedangkan yang terjadi di bagian selatan adalah adanya budaya saling curiga dan ketakutan akan proses reformasi institusi. Setelah adanya kajian ini Putnam kemudian memberikan definisi modal sosial yang berkaitan dengan warga (Field, 2014). Berbagai penelitian di Amerika, Putnam memberikan definisi modal sosial yang sudah dibuatnya menjadi sebuah bagian dari kehidupan sosial seperti jaringan, norma dan kepercayaan yang mendorong partisipan bertindak lebih efektif untuk mencapai tujuan bersama dimana kontak sosial antar partisipan mempengaruhi produktivitas partisipan itu sendiri (Field, 2014). Putnam Menyatakan modal sosial adalah bagian dari organisasi sosial, seperti kepercayaan, norma, jaringan (dari ikatan-ikatan masyarakat), yang dapat memperbaiki efisiensi masyarakat dengan memfasilitasi adanya koordinasi dan kerjasama bagi keuntungan bersama. Modal sosial juga di definisikan sebagai fitur organisasi sosial, seperti jaringan, norma dan kepercayaan sosial yang memfasilitasi koordinasi dan kerjasama (Primadona, 2017). 


\section{METODE PENELITIAN}

Penelitian ini menggunakan pendekatan penelitian kualitatif dengan metode deskriptif untuk mengungkapkan dan memahami realitas yang ada di lapangan sesuai dengan kondisikondisi sebenarnya pedagang sayur keliling. Metode pengumpulan data yaitu menggunakan observasi, wawancara mendalam dan studi dokumen. Unit analisis dalam penelitian ini yaitu rumah tangga pada masyarakat yang melakukan tindakan ekonomi yaitu pedagang sayur keliling. Analisis data menggunakan model pemikiran Miles dan Huberman.

\section{PEMBAHASAN}

\section{Manfaat Modal Sosial Bagi Pedagang Sayur Keliling}

Dalam artikel ini penulis menjelaskan cara kerja modal sosial pedagang sayur keliling berhubungan satu sama lain dalam ketahanan sosial rumah tangga dengan memanfaatkan modal sosial mereka. Pedagang sayur keliling di Mahakarya Kampung 2 berjumlah 15 orang lebih dominan perempuan dari pada laki-laki. Hal tersebut disebabkan karena perempuan bekerja untuk membantu perekonomian keluarga. Merujuk pada terminologinya Zusmelia (2012) keterlibatan perempuan dalam berdagang telah terjadi pergeseran dalam masyarakat dan berusaha terjun ke dunia publik selama ini didominasi laki-laki, sehingga mereka harus tampil sebagai penyelamat ekonomi rumah tangga (Zusmelia, 2012). Penulis akan menjelaskan bagaimana modal sosial pedagang sayur keliling dalam ketahanan rumah tangga.

\section{Kepercayaan}

Kepercayaan (Trust) menurut Fukuyama, adalah suatu Harapan yang tumbuh didalam masyarakat ditunjukkan oleh adanya perilaku jujur, teratur, dan kerjasama berdasarkan normanorma yang dianut bersama (Kimbal, 2015). Kepercayaan akan bangkit ketika setiap berbagai individu dan menemukan titik temu norma-norma bersama yang dicapai ketika masyarakat mampu berhubungan satu sama lain (Field, 2010).

Kepercayaan yang lahir antara pedagang dan pembeli di Mahakarya Kampung 2 dikarenakan saling jujur, sopan dan ramah kepada pelanggan serta memberikan pelayanan yang terbaik agar pelanggan semakin percaya dan sayur yang dijualpun harus segar. Berdasarkan hasil wawancara dengan pedagang sayur keliling dapat disimpulkan bahwa untuk mendapat kepercayaan pelanggan, pedagang sayur keliling bersikap jujur, ramah, sopan serta memperlakukan pelanggan dengan baik. Hal tersebut membuat pelanggan percaya nyaman dan percaya berlangganan dengan mereka. Manfaat dari kepercayaan yang diperoleh pedagang 
sayur keliling karena modal sosial yang ia miliki yaitu mampu memperluas jaringan. Selain kepercayaan tersebut, pedagang sayur keliling memperlakukan pelanggan tetapnya dengan istimewa dengan membolehkan cahs bon atau berhutang. Hal tersebut dilakukan agar pelanggan merasa nyaman berbelanja dengan pedagang sayur keliling. Maanfaat yang diperoleh dari kepercayaan pedagang sayur keliling karena modal sosial yang ia miliki yaitu terbangunnya kerjasama antara pedagang sayur keliling dengan pelangan.

Selain terbangunnya kerjasama karena kepercayaan dari pedagang sayur keliling tersebut, kepercayaan yang lain diberikan kepada pelanggan seperti penagihan hutang yang sudah jatuh tempo. Ketika pelanggan sudah jatuh tempo pedagang mengingatkannya, namun apabila pelanggan belum bisa melunasi hutangnya pedagang juga tidak memaksa. Hal tersebut terjadi karena pedagang sayur keliling percaya kepada pelanggan bahwa pelanggan akan tetap membayar walaupun telat. Manfaatnya yang diperoleh dari modal sosial yang ia miliki yaitu pelanggan setia dan tidak beralih ke pedagang lainnya. Berdasarkan hal tersebut dapat disimpulkan bahwa kepercayaan pedagang sayur keliling dengan pelanggannya terlihat kuat. Selain pedagang sayur yang memperbolehkan pelangganngan nya untuk cash bon atau berhutang akan namun ada beberapa pedagang sayur keliling yang tidak memperbolehkan pelanggannya untuk berhutang. Kepercayan yang terjalin antara pedagang sayur keliling dengan pelanggan dapat membantu ketahanan sosial rumah tangga contohnya seperti pedagang sayur keliling mampu mengangsur sepeda motor dan menyekolahkan anaknya sampai tinggi.

\section{Jaringan}

Terbentuknya jaringan sosial dipengaruhi oleh unsur modal sosial yang lain yaitu nilai/norma dan kepercayaan (trust), dua hal itulah yang akhirnya membentuk dan menguatkan jaringan. Nilai/norma dan kepercayaan tersebut mampu menguatkan jaringan sosial berupa arisan sesama pedagang lain. Sebagai seorang pedagang tentu adanya pelanggan merupakan komponen yang penting dalam keberlangsungan usaha mereka. Membangun hubungan baik dengan pelanggan dapat membantu kesuksesan seorang pedagang itu sendiri. Hal tersebut membuat pedagang sayur keliling bertahan dalam ketahanan sosial rumah tangga dengan pendapatan dibawah UMR. Jaringan yang terbentuk karena adanya nilai-nilai kebersamaan, tolong menolong dan kepercayaan diantara mereka.

Jaringan sosial pedagang sayur keliling di Mahakarya Kampung 2 terbentuk karena pelayanana yang diberikan pedagang sayur keliling cukup baik yaitu dengan bersikap jujur, 
ramah serta selalu memberikan sayuran yang segar-segar agar pelanggan merasa senang dan nyaman berbelanja dengan pedagang sayur keliling. Pernyataan tersebut sesuai dengan hasil temuan data di lapangan, penulis menemukan bahwa pedagang sayur keliling memanfaatkan hubungannya dengan para pelanggannya sebagai jembatan mendapatkan pelanggan baru. Hasilnya pelanggan memberikan informasi kepada teman mereka untuk berbelanja dengan pedagang sayur keliling.

Jaringan sosial tidak hanya antara pedagang sayur keliling dengan pelanggan akan tetapi antara pedagang dengan pedagang sayur keliling lainnya. Kedekatan dengan sesama pedagang dan terciptanya rasa saling tolong menolong diantara sesama pedagang, ketika pedadang sedang tidak mempunyai sayuran maka pedagang lain membantu mencarikan sayuran dan saling tukar sayur menggunakan system barter. Seperti hal lainnya yaitu apabila pedagang tidak berjualan, maka pedagang lain diperbolehkan menjual sayur ke pelanggannya. Jaringan yang terjalin tersebut terbentuk karena kerjasama antara keduanya. Hal ini sejalan dengan pandangan (Irwan et. al, 2020) menjelaskan bahwa kekuatan dari modal sosial mampu membentuk pelaku dan penyampaian tujuan bersama serta kemampuan untuk melakukan kerjasama. Jaringan sosial tersebut membuat perkumpulan arisan antara pedagang dengan pedagang, dimana hal tersebut dapat dijadikan tabungan sehingga pedagang sayur mampu bertahan dalam ketahanan sosial rumah tangga.

\section{Norma}

Setiap pedagang pasti memiliki nilai dan norma yang mereka terapkan kepada pelanggan mereka agar merasa nyaman dan timbul raya percaya antara mereka. Nilai yang dianut berupa nilai kesopanan, kejujuran, dan keramahan. Sebagaimana Fukuyama mengatakan bahwa kepercayaan adalah hasil sampingan yang penting dari norma-norma kerja sama sosial yang membentuk modal sosial. Kepercayaan meningkat apabila sama-sama menerapkan norma kejujuran dan norma timbal balik dan karena itu dapat bekerja sama satu sama lain (Fukuyama, 2005). Menarik dan mempertahankan pelanggan adalah dengan cara menerapkan nilai kesopanan, kejujuran dalam harga dan kualitas barang, dan keramahan kepada pembeli. Menurutnya, dengan bersikap baik, ramah dan menjalin hubungan baik dengan pelanggan akan bermanfaat bagi kelangsungan usahanya. Norma atau aturan anatara pedagang sayur keliling dengan pelanggan yaitu apabila pelanggan telat membayar atau jatuh tempo. 
Norma atau aturan yang telah disepakati bersama antara pedagang sayur keliling dengan pelanggan yaitu apabila pelanggan telat membayar hutang, maka pedagang sayur keliling mengingkatkan dan memberikan sanksi tidak akan memperbolehkan untuk berhutang sementara hutang tersebut belum terbayar. Hal tersebut membuktikan bahwa dengan norma/aturan yang berlaku tersebut maka seiring berjalannya waktu akan melahirkan kepercayaan diantara mereka. Manfaat modal sosial dari norma atau aturan tersebut mampu mempertahankan kepercayaan antara pedagang sayur keliling dengan pelanggan. Dengan begitu pedagang sayur keliling mampu bertahan dalam ketahanan rumah tangga dengan tidak membiarkan modal mereka berhenti karena pelanggan yang telat berhutang.

\section{KESIMPULAN}

Berdasarkan hasil pembahasan mengenai manfaat modal sosial dalam ketahanan sosial rumah tangga pedagang sayur keliling maka dapat ditarik kesimpulan sebagai berikut: Hubungan antara pedagang dan pembeli di Mahakarya Kampung 2 saling jujur, sopan dan ramah kepada pelanggan serta memberikan pelayanan yang, dengan kepercayaan yang dimililiki mampu menarik pelanggan. Selain itu memperbolehkan pelanggan berhutang merupakan salah satu cara agar pelanggan merasa nyaman dan yakin berbelanja kepada pedagang sayur keliling. Selain itu, pemanfaatan modal sosial tersebut yaitu memberikan hutang kepada pelanggan, dengan begitu pelanggan bertambah dan pend apatan meningkat serta selalu menjaga komunikasi yang baik sehingga mampu memperluas jaringan. Untuk memenuhi kebutuhan ekonomi rumah tangga yaitu melalui kesempatan berkerja sebagai pedagang sayur keliling, maka pedagang sayur mampu bertahan dalam ketahanan rumah tangga dengan terpenuhi kebutuhan rumah tangga serta ikut arisan dan menyekolahkan anaknya sampai tinggi.

\section{DAFTAR PUSTAKA}

Cahyaningtyas, A., Asih Amperiana Tenrisana, S. ., \& Dewi Triana, S. S. (2016). Pembangunan Ketahanan Keluarga. In . 2016. jakarta. dinas pemberdayaan perempuan.

Field, J. (2010). Social Capital. terjemahan Nurhadi. Bantul: Kreasi wacan.

Field, J. (2014). Modal Sosial. Yogyakarta: Kreasi Wacana.

Fukuyama, Fracis. 2005. Guncangan Besar: Kodrat Manusia dan Tata Sosial Baru. Terj Masri Maris. Jakarta: Gramedia Pustaka Utama.

Irwan, et al. (2020). Social Media Strengthens Social Capital in Dealing with Disaster on the 
Riverbanks. Bogor: International Journal of Innovation.vol 14(2), 397-416.

Kimbal, Rahel Widiawati. 2015. Modal Sosial dan Ekonomi Industri Kecil: Sebuah Studi Kualitatif. Yogyakarta: Deepublish.

Prasetya, E., 2006, Case Based Reasonin untuk mengidentifikasi kerusakan bangunan, Tesis, Program Pasca Sarjana Ilmu Komputer, Univ. Gadjah Mada, Yogyakarta.

Primadona, 2017. (2017). Pengaruh Modal Sosial Terhadap Keberhasilan Wirausaha di Kota Padang. 9(2), 55-73.

Rofiq, Ainur. 2007. Pengaruh Dimensi Kepercayaan (Trust) Terhadap Partisipasi Pelanggan. E conumerce (Studi pada pelanggan E comunerce di Indonesia). Tesis. Malang. Ekonomi Universitas Brawijaya.

Zusmelia. (2012). Keterkaitan Perempuan Pedagang Dengan Lahirnya Jiwa Enterpreneurship (Kasus Perempuan Pedagang di Pasar Nagari Minangkabau). Jurnal Sosiologi Andalas, XII(1), 91-102. 